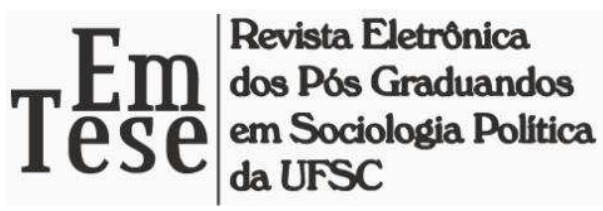

\section{PARA UMA SOCIOLOGIA DO CARISMA NA ATUALIDADE: ENSAIO PARA LEITURA DO CARISMA DE SAMORA MACHEL}

\author{
Hélio Bento Maúngue ${ }^{1}$
}

\section{INTRODUÇÃO}

Apesar de existirem figuras carismáticas na África e, particularmente, em Moçambique, ainda hoje, pouco se estuda sobre a influência que as suas figuras carismáticas exercem na estrutura cotidiana dessas sociedades. Impressionante é como a força do carisma e a exploração racional dele supera a morte física da personalidade carismática, tornando-o, pode-se dizer, "mais vivo" do que quando vivo. Mas como essas personalidades carismáticas continuam influenciando nas formas de ser e estar de seus seguidores e admiradores? Como se alimenta a relação emocional entre o líder carismático e seus seguidores depois de sua morte? Analisar o carisma para além da dominação carismática que a personalidade detém é desafio revigorante para as ciências sociais e particularmente para a sociologia em Moçambique, daí a ideia deste artigo.

O conceito weberiano de carisma está ligado a um problema de explicação, por isso, o carisma deve ser visto como um modelo de explicação e como chave sociológica para se compreender os usos e apropriações que se faz atualmente das qualidades extracotidianas que representam as personalidades carismáticas.

Samora Moisés Machel (29/09/1933 - 15/10/1986) é uma figura que marcou, e tem marcado gerações, em Moçambique pelos seus discursos, entrevistas e intervenções apaixonantes (MAÚNGUE et al., 2012) bem como pelo construto social de uma vida dedicada a trazer mudanças na sociedade moçambicana. Neste sentido, falar e refletir

\footnotetext{
1 Mestrando em Sociologia Política da Universidade Federal de Santa Catarina. Graduado do Centro de Estudos Africanos/Universidade Eduardo Mondlane (CEA/UEM).
} 


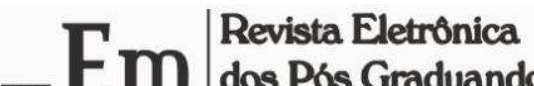

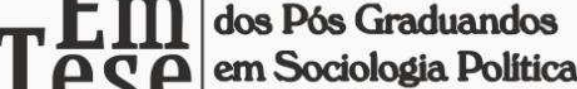 da UFSC}

sobre uma figura com a dimensão de Samora, em função do carisma que tem no seio da sociedade moçambicana, é de extrema importância e ao mesmo tempo uma tarefa desafiadora.

No presente artigo a intenção não é refletir essencialmente sobre o fenômeno carismático que é Samora, algo conhecido e reconhecido em Moçambique, mas sim sobre os possíveis usos e apropriações que se faz das personalidades carismáticas, no caso especifico, de Samora. Deste modo a intenção é apreender quais são os atores que fazem uso do carisma samoriano para obter diferentes "benesses". Ao fazê-lo, esses atores tornam viva a personalidade e a qualidade extracotidiana que Samora representa, resamorizando as concepções de vida e mentalidades dos moçambicanos.

A abordagem que seguimos no artigo, leva-nos a cogitar que o carisma poder ser apropriado e usado de acordo com fins específicos, mas, ao mesmo tempo, essa ação ajuda a manter uma relação emotiva entre o portador do carisma e a "comunidade" carismática que surgiu e que se desenvolveu em volta do mesmo. Essa relação pode ser contextualizada em função do uso que se faz dessa personalidade carismática e serve para destacar que o vínculo emocional entre o líder carismático e sua comunidade de seguidores e de admiradores pode prevalecer mesmo depois da morte da personalidade carismática, isto é, tenta-se negar a rotinização do domínio carismático que ocorre na perspectiva weberiana, peremptoriamente. Assim, o artigo discorre sobre a questão da continuidade do carisma samoriano e da manutenção da relação emocional entre o líder (Samora Machel) e o povo moçambicano, relação essa que se sustenta, ainda hoje, 28 anos depois de sua morte.

Neste sentido, o termo carisma e a noção da relação emocional enfatizadas por Weber (1982, 1994), são instrumentos importantes para fundamentar estudos sobre os usos das figuras carismáticas, bem como demonstrar que as benesses que conseguem os atores que fazem uso ou apropriação do carisma são produto concreto de uma emoção que liga o líder carismático ao povo. Povo que continua idolatrando-o, tornando esse processo uma reelaboração da memória coletiva estabelecida pela personalidade de Samora.

Para a nossa iniciativa, no segundo capítulo do artigo procuramos apresentar uma breve revisão das reflexões contemporâneas sobre o carisma e da autoridade

Em Tese, Florianópolis, v. 11, n. 1, jan./jun., 2014. ISSN: 1806-5023 


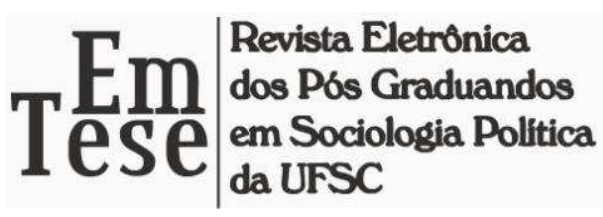

carismática; no terceiro capítulo procuramos contextualizar aos nossos leitores quem é Samora Machel; em seguida, no quarto capítulo esboçamos possíveis usos do carisma samoriano na atualidade e; por último as conclusões da nossa análise.

\section{O CARISMA NA CONTEMPORANEIDADE}

No presente capítulo procuramos explorar, brevemente, o conceito weberiano de carisma e trazer ao texto os usos e/ou aplicações que se fazem desse conceito no mundo contemporâneo. Portanto, não se fará uma exegese nem do conceito de carisma e muito menos da sociologia de dominação carismática weberiana, mas, um apanhado que sirva de enquadramento para entender a liderança enquanto problema político e social na sociedade moderna, merecedor de uma reflexão acadêmica.

O conceito de carisma, associado à noção de dominação carismática, é um dos conceitos-chave para quem deseja adentrar e entender a sociologia weberiana, especificamente à sua sociologia política, na sua vertente da sociologia da dominação a par das outras formas de legitimação da dominação analisadas por Weber, nomeadamente a dominação tradicional e a legal (WEBER, 2004).

O conceito de carisma é um dos mais notáveis exemplos dos conceitos weberianos. Weber continua informando e estimulando reflexões e pesquisas empíricas e teóricas (GREEN, 2008), nas ciências e sociologia política contemporânea. Para Weber (2004) o carisma é termo técnico sociológico, que diferentemente das duas outras formas de autoridade (a tradicional e a legal/racional) é baseado em poderes enigmáticos de personalidades individuais para incitar confiança e segurança, na maioria das vezes ao serviço de um grande propósito ou missão (ibid.).

Neste sentido, o carisma é:

A certain quality of an individual personality by virtue of which he is considered extraordinary and treated as endowed with supernatural, superhuman, or at least specifically exceptional powers or qualities. These are such as are not accessible to the ordinary person, but are regarded as of divine origin or as exemplary, and on the basis of them the individual concerned is treated as a 'leader' (WEBER apud GREEN, 2008, p.189). 


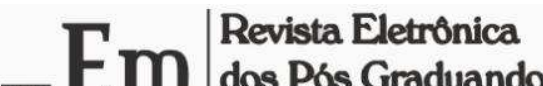

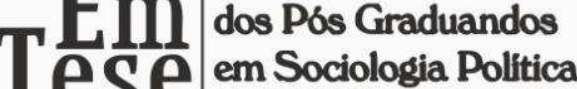 da UFSC}

No entanto, a forma pura de carisma, conforme aborda Weber (2004) podemos encontrar em personalidades religiosas, profetas, magos, chefes de guerra, chefes das expedições de caça (SERRA, 2003). Contudo, essas figuras, dotadas de qualidades pessoais e extracotidianas, que conseguiam atrair para si seguidores, mas que aparecem raras vezes na história mundial como, por exemplo, os "founders of religion like Moses, Jesus and Mohamed, the biblical prophets, magicians offering healing through occult powers, and political geniuses like Pericles, Caesar, or Napoleon" (GREEN, 2008, p. 189).

No mundo sociopolítico contemporâneo estas personalidades não aparecem com suas características genuínas, na medida em que a pureza do carisma vai sendo afetada, de modo que vêm sofrendo transformações, ocorrendo uma objetivação do carisma, de modo especial, quando surgem às instituições ou a perspectiva racional em virtude do aumento dos poderes institucionais, perdendo as figuras carismáticas suas bases transcendentais (CARDOSO, 2011). Segundo Segre (2000, p. 152, tradução nossa) "a autoridade carismática é inerente e pertence ao escritório, em vez de pertencer à pessoa". Acrescenta Cardoso (2011, p. 105) que isto dentro de um partido "um determinado político pode apresentar traços do carisma”. Em suma, dada as atuais condições conjunturais elabora-se um novo tipo ideal de carisma, segundo as indicações metodológicas propostas por Weber (2001).

Esta forma de como o carisma se manifesta no mundo contemporâneo, sem seus traços genuínos, tal como o das personalidades que nos referimos anteriormente, faz surgir uma nova vaga de lideranças carismáticas no contexto das democracias atuais. Para Green (2008) esse cenário faz com que a democracia plebiscitária crie lideranças carismáticas manufaturadas, isto é, a democratização faz com que ascenda a condição de "quasi-charismatic leaders" que conseguem garantir uma base de apoio e seguidores que contribuem para seu surgimento e manutenção enquanto chefe do governo, criando e mantendo uma relação emocional líder/povo. Essas figuras carismáticas manufaturadas ou quase-charimatic leaders são configurações de um tipo ideal de carisma na contemporaneidade. 


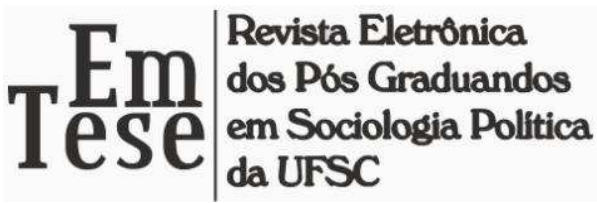

Um dos exemplos mais presentes no mundo contemporâneo dessa relação emocional entre o líder e o povo, que o conceito de carisma enaltece, é a reflexão sobre o conceito de populismo. Sobre isso Sell (no prelo), diz que a ideia de culto a personalidade é aspecto marcante dessa relação emocional, e o populismo, "um subtipo de dominação carismática”. Aqui estamos diante de figuras carismáticas, que auferem muita popularidade e simpatia perante uma grande legião de admiradores e seguidores, na sua maioria oriunda das classes mais desfavorecidas da sociedade e que com elas estabelecem uma relação emocional. Sem, no entanto, excluir os indivíduos com condições socioeconômicas consideravelmente favorecidas. Os admiradores/seguidores têm muita afeição e identificação com o respectivo líder.

Fugindo um pouco das reflexões sobre a liderança carismática dentro do contexto da sociologia e ciências políticas contemporâneas, encontramos a aplicação do conceito weberiano para analisar a presença de líderes carismáticos nas organizações. Os estudos atuais sobre o conceito de carisma aumentaram significativamente no interior da chamada teoria das organizações, na medida em que se procura ver a dominação carismática para além de um conjunto de qualidades extraordinárias de um indivíduo. Isto se dá porque a pesquisa contemporânea sobre a presença do carisma tende a reduzi-lo ao fenômeno da indução e aceitação da liderança, entusiasmo, motivação ou engajamento pró-grupo (GAST, 2008, apud SELL, no prelo).

A aplicação do conceito de carisma também é utilizada para entender os movimentos carismáticos que incluem a idolatria de heróis esportivos, figuras do entretimento que marcam a moderna cultura ocidental. Neste sentido, estrelas de cinema, atletas, cantores, artistas famosos e outros ícones, são considerados figuras carismáticas. Aqui a ação/performance por eles desempenhada é um atributo importante para conquistar admiradores. Isto ocorre na medida em que, essas figuras, proporcionam cenários para reunião de multidões e para uma expressão de uma unidade carismática entre seus fãs (LINDHOLM, 1993). Por mais que seja um modo fugaz de incitação, há momentos que ocorre uma relação emotiva entre fãs e ídolos. Este aspecto faz despertar olhares para outros campos sociais de manifestação carismática também entre personalidades não políticas e uma legião de seguidores. Isto é, existem outros 


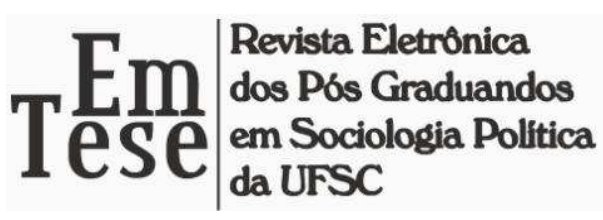

segmentos da sociedade em que podemos vislumbrar a existência de personalidades carismáticas, como o do segmento religioso.

Lindholm (1990), olhando novamente para personalidades não políticas, destaca as manifestações carismáticas nas religiões modernas. $\mathrm{O}$ autor destaca os lideres das religiões pentecostais, e podemos acrescentar as neopentecostais ${ }^{2}$, onde a capacidade do pregador carismático incita na congregação momentos de êxtase que valida uma fé religiosa compartilhada. Tal atitude arrasta com o pregador carismático uma grande legião de crentes seguidores, com expressividades carismáticas, e aqui a emoção volta a ser um elemento presente quando os devotos permanecem leais aos líderes-pregadores.

Estas aplicações do conceito de carisma demonstram que o mesmo é importante para a compreensão de como estão estruturadas as sociedades, bem como alguns seguimentos delas. Deste modo a forma de ser e estar, realçando o papel das emoções/paixões no despertar de ações coletivas em contextos específicos, bem como de ações emocionalmente fundamentadas que um grupo de pessoas se comporta como parte integrante dos contextos onde essas manifestações carismáticas que surgem na atualidade.

\section{QUEM É SAMORA MOISÉS MACHEL (1933-1986)}

Samora Machel, amado por muitos, odiado por outros; figuras históricas desta grandeza suscitam sentimentos tão contraditórios, mas se cruzam e são unânimes num aspecto: ele marcou uma época e igual a ele levará séculos a brotar em Moçambique. (Arão Litsure, pastor da igreja congregacional, depoimento retirado de TEMBE, 2001, p. 14).

Ao refletir sobre uma personalidade convém situá-la e contextualizá-la. Neste capítulo vamos apontar alguns aspectos da personalidade de Samora Machel. Não se trata de uma biografia breve dessa personalidade, mas uma tentativa de enquadrar o porquê da figura carismática de Samora Machel, principalmente em Moçambique.

\footnotetext{
${ }^{2}$ As religiões pentecostais e neopentecostais são muito efervescentes no continente Americano, tanto na América do Norte, como na América do Sul. Contudo, as mesmas têm atravessado oceanos chegando a outras partes do mundo.
}

Em Tese, Florianópolis, v. 11, n. 1, jan./jun., 2014. ISSN: 1806-5023 


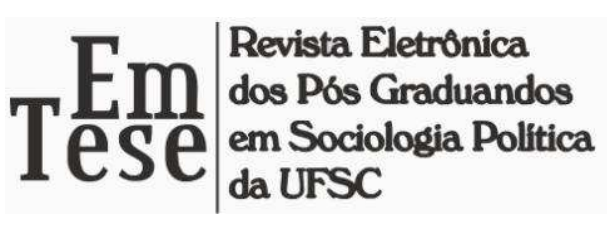

$\overline{\text { Falar do } \text { Marechal }^{3} \text { Samora Moisés Machel para os de Moçambique, para os da }}$ África, e da África Austral, em particular, pode não constituir novidade, uma vez que as pessoas desses lugares sabem do seu empenho nos movimentos de libertação nacional contra o colonialismo em Moçambique, e, indiretamente em alguns países vizinhos a este. Outro aspecto que marca a sua personalidade são as circunstâncias de sua morte, vítima de acidente aéreo em Mbuzini ${ }^{4}$, na vizinha África do Sul, quando Samora e mais 33 membros de sua delegação regressavam de uma missão de paz na Comunidade de Desenvolvimento da África Austral (SADC).

$\mathrm{Na}$ época que ocorreu o acidente, Samora Machel, era considerado em África e internacionalmente, um dos mais excepcionais guerrilheiros e líderes políticos do seu tempo. Para seu próprio povo, o povo moçambicano, para quem a libertação do colonialismo português ele contribuiu enormemente, ele era mais do que isso. Aos olhos desse povo, ele era um disciplinador, querido pai, irmão, amigo, admirado e digno de confiança. Para o seu exército de guerrilheiros ele era o Comandante Amigo. O moçambicano o chamava, e ainda hoje, o trata afetuosamente de Bava 5 /Papa Samora (MANGUEZI, 2001).

Quando ocorre a sua morte, Moçambique vivia uma guerra civil ${ }^{6}$, e alguns países da região atravessavam momentos de muita turbulência política. Esses acontecimentos fazem com que a figura de Samora marcasse um período importante no continente africano - o fim do processo de independência em África, sendo que sua presença foi decisiva para a libertação da África Austral, referindo-nos explicitamente ao Zimbabwe, Namíbia e África do Sul, pondo fim aos regimes fascistas e racistas. Mas, a ânsia de Samora pela libertação dos povos em África estendeu-se a outros países e continentes, numa solidariedade sem reservas e sem contrapartidas (SOPA, 2001). Esse fato contribui para que Samora seja percebido como um homem extraordinário, um revolucionário que tinha um compromisso com a independência dos povos de todo o mundo (TEMBE, 2000).

\footnotetext{
${ }^{3} \mathrm{O}$ cargo mais elevado na hierarquia militar moçambicana.

${ }^{4}$ Região de colinas na África do Sul, sendo que o acidente ficou nominado de acidente de Mbuzini.

${ }^{5}$ Significa pai em algumas línguas maternas, especificamente no sul de Moçambique, contudo passou a ser e ainda é a marca e símbolo da ligação e relação emocional da figura e carisma de Samora com o povo moçambicano.

${ }^{6}$ Denominada guerra de desestabilização que durou 16 anos (1976-1992).
}

Em Tese, Florianópolis, v. 11, n. 1, jan./jun., 2014. ISSN: 1806-5023 




Esse desejo de ver seu país tornar-se independente é manifestado ainda durante a sua juventude. Ao contrário de muitos outros jovens moçambicanos da sua época, ele abriu mão da possibilidade de obter uma bolsa de estudos a ser oferecida por Eduardo Mondlane $^{7}$. A ida de Mondlane a Moçambique era vista como uma possibilidade de seus jovens irem estudar nos Estados Unidos, Samora foi um dos poucos que quis "colocar-se ao serviço da revolução", abandonando, inclusive, a sua profissão de enfermeiro (GANHÃO, 2001).

É como enfermeiro que ele começa a desenvolver suas atitudes revolucionárias principalmente contra as atrocidades que o sistema colonial praticava contra os mais fracos, num enfrentamento aberto aos portugueses, uma vez que ele era rebelde e desafiava os colonizadores. Ele, por exemplo, não aceitava que os negros moçambicanos se levantassem (como sinal de respeito) sempre que um administrador colonial ou outro colonizador branco passava onde havia negros moçambicanos, os encorajando a não se deixarem subjugar. Este fato lhe valeu perseguições por parte da máquina administrativa colonial, e isso o levou a se unir a outros moçambicanos que se interessavam com o propósito da revolução (MAÚNGUE et al., 2012).

Este ato de Samora marca o início de sua entrega à causa da libertação do povo moçambicano contra a exploração colonial portuguesa e que era "uma inimiga a abater", marcando "início" e desenvolvimento da sua personalidade carismática. Essa personalidade ganhou protagonismo com o fim do colonialismo e com a proclamação da independência, em 25 de junho de 1975. Nesta data, Samora proferiu o discurso que marcava o fim do colonialismo e, ele tornou-se o primeiro presidente de Moçambique independente. Isso foi o marco para a instauração de uma época denominada samoriana $^{8}$, na medida em que:

O primeiro presidente moçambicano foi mais que um ser: ele fundou um tempo que hoje leva seu nome. O que torna esse tempo objeto de miragens e fantasias é que ele constitui a nossa infância, nele se inscrevem os primeiros passos da nossa cidadania (tirado do prefácio TEMBE, 2000, feito pelo escritor Mia Couto).

\footnotetext{
7 Nacionalista e pan-africanista moçambicano, fundador e presidente da Frente de Libertação de Moçambique (FRELIMO), hoje transformado em partido que está no poder desde a independência de Moçambique do colonialismo português.

${ }^{8}$ Cujo fim chegou com a sua morte em 1986.
} 




Para o sociólogo moçambicano Carlos Serra (2003) samorismo é "o conjunto de crenças, de práticas e de métodos utópicos que se estruturou no imaginário popular por consenso e recusa no que concerne ao falecido presidente Samora Machel". Esse autor ainda acrescenta que o samorismo é

\begin{abstract}
Menos o conjunto dos atributos possuídos "em si" por Samora, do que o conjunto de expectativas (elas também) e de identificações projetadas pelas pessoas em Samora. É nessa relação que nasce e se consolida o fenômeno carismático samoriano, 'carisma intenso e concentrado' como diria Shils, é nessa relação que se criam e irradiam as identidades utopiano-populares da revolução (SERRA, 2003).
\end{abstract}

O que ocorre é uma exemplificação do carisma como um tipo ideal weberiano, isto é, é uma construção que se reveste de uma utopia. Utopia essa, projetada pelos seguidores e admiradores de Samora, é "obtida mediante a acentuação mental de determinados elementos da realidade" (WEBER, 2001, p. 137) como os que apresentaremos mais em frente. Neste sentido, a existência do samorismo é como representação de uma ligação forte entre a personalidade carismática de Samora e o povo moçambicano, mesmo depois de quase três décadas de sua morte.

Pessoas como Samora são tão marcantes que não resta outra solução ao homem médio moçambicano, se não ser seu mero representante, ou mero suporte de uma dada condição histórica do país preenchida por Samora. Mesmo aqueles que de alguma maneira são samorianos, quer dizer parecidos do estilo, da essência, do brilho carismático de Samora, como o presidente de Moçambique eleito em 2004, que ao tomar posse no seu primeiro mandato era visto como um samoriano, mesmo esses são instintivamente apagados, submersos pela individualidade samoriana. Resumindo, são homens médios diante da personalidade de Samora (SERRA, 2003).

Portanto, weberianamente falando, ao lado de uma figura como Samora estamos diante de uma personalidade carismática e dotada de características extracotidianas como atesta sua viúva ao dizer que "quando Samora entrava numa sala, toda a gente sabia que alguém tinha entrado" $9 "$ (SERRA, op cit., p. 58).

\footnotetext{
${ }^{9}$ Entrevista conduzida por Emilio Manhique, fita cassete produzida e editada pela Rádio Moçambique, 1995, faixa B (SERRA, 2003).
}

Em Tese, Florianópolis, v. 11, n. 1, jan./jun., 2014. ISSN: 1806-5023 


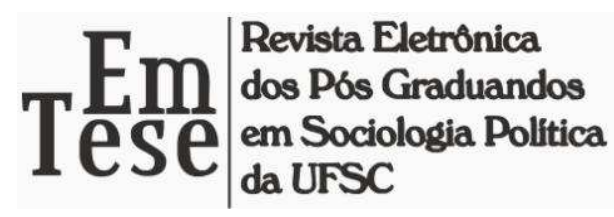

\section{DA APROPRIAÇÃO DO CARISMA SAMORIANO}

\begin{abstract}
E mesmo quando o poder que ele encarnava abriu as primeiras fissuras, era ainda nele que todos acreditavam. Hoje, perante a realidade difícil em que vivemos, é, muitas vezes, Samora que recordamos. Samora vive em cada um de nós, parafraseando um slogan de alguns anos atrás. A sua imagem vive dentro dos "condenados da terra", daqueles que nada têm, e que um dia sonharam ser Homens. Daqueles que acreditavam alguma vez numa sociedade diferente, de maiores liberdade e justiça social (SOPA, 2001, p. 5).
\end{abstract}

Neste capítulo, procuraremos esboçar as diferentes formas que, atualmente, diferentes atores sociais podem fazer ou fazem uso das qualidades carismáticas que uma personalidade pode ter, em seu beneficio próprio. No presente caso, como na contemporaneidade moçambicana os indivíduos procuram obter ganhos se apropriando e usando do carisma samoriano. No entanto, no ato de se usar do carisma samoriano para obter ganhos existe um elemento central e simbolicamente importante, na medida em que é e/ou ressurge como um catalisador das ações perpetradas pelos atores. Estamos falando das emoções, ou seja, da relação emocional que se estabelece entre o líder carismático e o povo. O que se vislumbra nos dias de hoje quanto ao uso da personalidade carismática de Samora Machel, é uma recuperação da emoção que permeava a relação entre Samora Machel e o povo (LANGA, no prelo).

Contudo, na nossa forma de "ler" o fenômeno do uso da personalidade carismática samoriana é de um processo de resamorização das concepções da vida (SERRA, 2003), na medida em que ocorre um apelo ou chamamento/re-chamamento da figura de Samora em diferentes esferas e situações da vida social moçambicana. Este processo de resamorização da vida traz Samora como uma espécie de memória coletiva sempre presente no cotidiano dos moçambicanos. Samora torna-se um fenômeno social possível pelo uso que os diferentes atores sociais fazem dessa personalidade, apropriando-se de seu carisma, como vamos procurar elucidar nos parágrafos que se seguem.

Atualmente o carisma samoriano pode ser usado na esfera do político quando o seu nome e os seus ideais são constantemente apelados pela classe política em seus discursos, quer em datas comemorativas, principalmente nos principais feriados

Em Tese, Florianópolis, v. 11, n. 1, jan./jun., 2014. ISSN: 1806-5023 


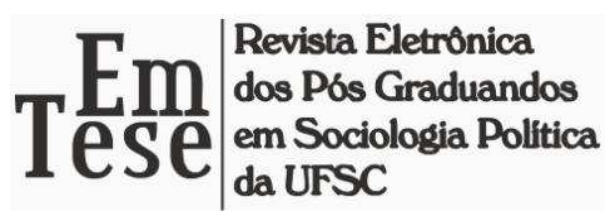

nacionais, quer em discursos políticos no período da campanha eleitoral para convencer o eleitorado. Este aspecto do uso político da personalidade carismática de Samora não escolhe cor partidária e nem hierarquia dirigente nos diferentes partidos políticos existentes em Moçambique. Assim, quer o partido FRELIMO, partido que trouxe a independência nacional, no qual Samora ganhou simpatia e conseguiu conquistar e manter-se como uma autoridade carismática, quer os demais partidos existentes no país, todos eles, principalmente nos pleitos eleitorais, dizem serem seguidores dos ideais políticos de Samora Machel. Uma ação estratégica para ganhar simpatia diante do povo e/ou eleitorado.

Ainda, na esfera política, um aspecto recente de uso da personalidade samoriana se deu quando da implantação e inauguração de estátuas da figura de Samora Machel ${ }^{10}$ em todas as capitais provinciais do país. Ato concebido pelo governo. Neste ponto, podemos supor uma espécie de culto a personalidade do presidente Samora, bem como uma possível manifestação de populismo, via carisma samoriano. Contudo, este reavivar da figura de Samora, por via das estátuas espalhadas pelo país afora, pode ser também uma ação estrategicamente perpetrada pelo Governo para ganhar simpatia perante o povo que, manifestamente, ainda idolatra Samora.

Tais aspectos nos fazem pensar que o mundo da política é um mundo do espetáculo, de onde surgem ídolos e de onde os discursos se assemelham aos de ocasiões festivas, como comícios, as músicas ${ }^{11}$ e os debates. Contudo, o personagem político que se insere na imagem de herói, como Samora, apesar de suas qualidades peculiares, não sobreviveria jamais, sem o constante ressurgir da imagem carismática.

Outra questão do uso político do carisma samoriano é o apelo de sua figura para solucionar alguns males que "enfermam" o Estado/Governo como destaca em entrevista Jorge Rebelo ${ }^{12}$

Há quem busca a referência para o combate à corrupção em confissões religiosas, entretanto, a solução mais próxima são as figuras de Samora e

\footnotetext{
${ }^{10}$ É de realçar que o ano de 2011 foi consagrado pelo governo moçambicano como Ano Samora Machel, ano em que sua figura ressurgiu e repovoou as mentalidades das pessoas que aglutinam na mesma personalidade diferentes tipos de referências, desde o estadista, político, militar, amigo, pai, entre outros (MAÚNGUE, et al., 2012).

${ }_{12}^{11}$ Aspecto que voltaremos a abordar mais adiante.

${ }^{12}$ Apontado como uma reserva do "samorismo".
} 




Eduardo Mondlane, pois deixaram lições e definiram a corrupção como mal a combater (BELMIRO \& BANZE, 2010).

Aliado a este chamamento político da personalidade samoriana como solução dos males presentes na sociedade moçambicana, está o fato de na esfera sociocultural o nome de Samora ressurgir no cotidiano dos moçambicanos em várias formas de manifestação cultural como destaca o filósofo moçambicano Severino Nguenha. Ele aponta que depois de anos de silêncio em torno do nome Samora, a figura dele de repente, começou a ser ressuscitada nos "chapas ${ }^{13}$ ", no teatro, nos rapes $^{14}$. Uma necessidade de confrontar a nova orientação do país com os ideais passados, mas talvez não ultrapassados (NGUENHA, 2009).

Neste sentido, estamos diante de um ambiente de saudosismo e de crescente nostalgia visível em face da personalidade de Samora. Nos transportes públicos, nas lojas, nos mercados populares, no comércio informal e, até nas casas das pessoas se ouvia e se ouve a voz de Samora irromper, projetada pelo som de aparelhos audiovisuais como rádio, gravadores, discos compactos e vídeos, fazendo com que a imagem dele habite e ilustre as $t$-shirts [bonés e algumas tatuagens corporais], os chapas, viaturas individuais através de pinturas adesivas, e as pinturas em grafite nos murros das cidades. Samora está mais vivo do que quando vivo, sendo o regresso do morto, em forma de memória coletiva (LANGA, no prelo).

Há que se destacar que a reprodução em vídeo e áudio dos discursos e intervenções de Samora Machel deu-se marcadamente no comércio informal, mas também em nível oficial promovido pelo Ministério da Cultura que também reproduz e comercializa esse conteúdo, contudo, com preços bem diferentes e mais elevados que os do comércio informal.

Este uso, sociocultural, da personalidade samoriana nos chapas, no teatro e na música [principalmente no hip-hop como meio de intervenção social], em lojas, nos automóveis individuais, $t$-shirts, bonés é marcado como sendo uma forma de contestação do dirigismo político atual que não se pauta pelos ideais socialistas característicos da governança samoriana, cuja marca era sua preocupação com o bem

\footnotetext{
${ }^{13}$ Nome de meio de transporte rodoviário de passageiros em Moçambique, de caráter privado e que varia de 15 a 47 lugares.

${ }^{14}$ Ou seja, hip-hop.
} 




estar social do povo, principalmente daquela camada mais pobre da população. Esse chamamento samoriano se manifesta como uma crendice popular, como se fosse verdadeira (autêntica), pois ele sairia da tumba (praça ${ }^{15}$ ) para impor a ordem neste país (TEMBE, 2000).

Nestas manifestações está visível que Samora é ainda hoje, passados tantos anos de sua morte, visto como o Messias que "salvará" o povo reativando os sentidos da vida, principalmente na camada mais pobre da sociedade moçambicana, como destaca o sociólogo moçambicano Carlos Serra em entrevista ao apontar que:

\begin{abstract}
Há uns anos atrás, uma pesquisa por mim conduzida mostrou que, nos bairros periféricos da cidade de Maputo, Samora surgia como uma espécie de messias, de figura forte, de figura nobre, como uma espécie de justiceiro, de redentor que, se fosse vivo, acabaria com o roubo, com os assaltos, com a malandragem, com a intranquilidade, com as injustiças sociais. [Sendo que] em certos momentos da vida, consoante às percepções que dela temos, especialmente se más forem, fazemos intervir simbolicamente nos nossos desejos de reequilíbrio social figuras do tipo samoriano, tornadas mitos redentores, alternativas de vida (Verdade, 2012).
\end{abstract}

Na fala de Carlos Serra (2003, p. 35) Samora é invocado e chamado como aquele que virá restabelecer certa ordem na forma como a vida está correndo, isto é, "Samora seria a resposta à necessidade popular de ordem, de cosmos organizado, de coerência, de continuidade e de justiça".

Aspectos que fizeram proliferar de modo vertiginoso a produção de $t$-shirts e bonés com a sua imagem, como se fosse uma marca de grife ${ }^{16}$, também impulsionou a reprodução de discos em formato áudio e vídeo com seus discursos e produção de pinturas adesivas com sua imagem para uso em automóveis. A imagem de Samora torna-se um "produto" comercializável, ocorrendo uma apropriação e uso socioeconômico da figura e personalidade de Samora. Este uso socioeconômico também foi empregado por artistas, principalmente do teatro e da música, para que seus "produtos" fossem objeto de atração e de desejo por parte do público consumidor.

Portanto, economicamente, o carisma samoriano é apropriado de diferentes formas, constituindo uma forma de renda e de lucro pelos atores sociais ligados as

\footnotetext{
${ }^{15}$ Praça dos heróis, onde jazem os restos mortais dos heróis da luta de libertação de Moçambique contra o colonialismo português.

${ }^{16}$ Fato semelhante foi possível ver com figuras com Che Guevara, Bob Marley e Nelson Mandela.
} 


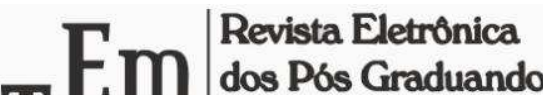

 da UFSC}

atividades de caráter comercial (formal e informal). Deste modo a personalidade carismática de Samora passou a ser um bem comercializável e de uso.

Portanto, a apropriação e uso da personalidade samoriana por diferentes atores sociais e para diferentes fins (políticos, socioculturais e socioeconômicos), faz com que, mesmo depois de morto, o carisma de Samora Machel mantenha-se vivo e presente no cotidiano. Ele continua sendo clamado nas mais diferentes formas de vida em sociedade, como se tratasse de um homem que morreu e não morreu (TEMBE, 2000).

\section{CONSIDERAÇÕES FINAIS}

Foi proposta deste artigo mostrar que a personalidade carismática de Samora Machel está presente no cotidiano dos moçambicanos em função dos "artifícios", quer de políticos, quer de artistas, quer de cidadãos comuns os quais ao usarem para diferentes fins, ajudam a tornar viva a personalidade carismática que Samora representa na e para a sociedade moçambicana. Assim, o processo de resamorização e/ou apelo/chamamento que os diferentes atores sociais fazem do carisma samoriano, tomando o pensamento weberiano, é útil para pensar a manutenção do vínculo emocional que existe entre um líder carismático como, Samora Machel, mesmo após sua morte.

Portanto, mesmo que ocorra esse uso e apropriação para fins político, cultural e econômico por parte de diferentes atores e instâncias sociais, nele são/estão expressas manifestações das emoções. O tempo não faz desaparecer esse vinculo emocional entre Samora e seu povo. A "comunidade emocional" que o carisma samoriano gerou se mantém e perdura com o tempo. Porém, os diferentes atores geram uma disputa pelo legado samoriano, executando, para tal, ações racional e instrumentalmente fundamentadas em expectativas dos seguidores e admiradores de Samora. Isto é, os atores que usam dos ideais samorianos têm a noção que o fazendo, das diferentes formas que apontamos, irão impactar nas formas de ser e estar dos indivíduos e influenciar nos seus comportamentos e, consequentemente satisfazem as suas necessidades. 


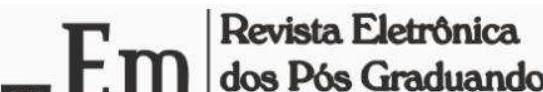 \\ TeSe da UFSC}

Contudo, o uso/apropriação do carisma samoriano no sentido que procuramos refletir neste artigo faz com que certa objetivação dessa relação emocional entre o líder e o povo, seja manifestada, na medida em que os atores sociais exploram esse carisma para obter diferentes ganhos, e o fazem de forma racional e calculada, para atingir determinados fins políticos, socioculturais e socioeconômicos. Assim, há uma "racionalidade" por parte dos que se apropriam e fazem uso do carisma samoriano. Através disso conquistam coisas objetivas como dinheiro, fama (por mais que possa ser visto como algo emotivo) e poder (sem exatamente ser por via de transferência do carisma). No entanto, é um mecanismo de manter-se uma relação entre o líder e o povo.

Mas, fora a presença do elemento racional que os usuários do carisma samoriano fazem, o reaparecimento dessa figura na atualidade, weberianamente falando, passa de um fenômeno extraordinário para um fenômeno ordinário. Ganhando elementos objetivos e, por conseguinte processa-se uma rotinização do carisma samoriano. Todavia, é um carisma que se rotiniza numa mesma pessoa, apesar de morta, e não se consegue transferir para outrem. O carisma reacende na mesma personalidade por diferentes atores, em função dos momentos/situações e dos interesses que esses atores fazem uso ou se apropriam dessa personalidade carismática.

O perdurar do carisma samoriano se manifesta igualmente pela crença, em suas qualidades extracotidianas, por parte de seus seguidores no sentido de que ele (Samora) ainda é uma força revolucionária. Seus feitos (um dos critérios weberianos para obediência ao chefe carismático), enquanto era vivo, são motivos para ele ser "clamado/chamado" pela sociedade moçambicana, tornando vivo o fenômeno, carismático, Samora Machel.

Portanto, o fenômeno Samora Machel é um processo atual e coletivo que serve, devido a sua potência carismática, como meio de a sociedade questionar um presente diferente, tornando o carisma como qualidade e capacidade permanente da vida cotidiana. 


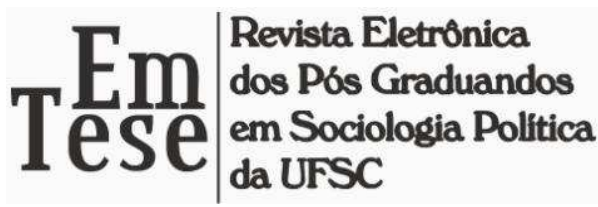

\section{REFERÊNCIAS}

Arquivo Histórico de Moçambique. Subsídios para a biografia de Samora Machel. Boletim do Arquivo Histórico de Moçambique. Maputo, out., 1995, n. 18, p. 129-168.

BACH, Maurizio. Carisma e racionalismo na sociologia de Max Weber. Antropologia \& Sociologia. Rio de Janeiro, 2011, v. 1, n. 1, p. 51-69.

BELMIRO, José \& BANZE, Sérgio. Há ministros que enriquecem a custa do sofrimento do povo. O PAÍS. Maputo, 20 out, 2010, Entrevista, p. 5-6.

CABRITA, João M. A Morte de Samora Machel. Maputo: Edições Novafrica, 2005.

CARDOSO, Ramos M. Os riscos da modernidade e o líder carismático. Revista Húmus. Minas Gerais, maio/jun/jul/ago., 2011, n. 2, p. 100-109.

CHRISTIE, Iain. Samora uma biografia. Maputo: Ndjira, 1996.

GANHÃO, Fernando. "Samora Machel: um relâmpago no céu”. SOPA, António (Coord.). Samora, homem do povo. Maputo: Manguezo Editores, 2001.

GREEN, Jeffrey Edward. Max Weber and the reinvention of popular power. Max Weber Studies. London, 2008, v. 8, n. 2, p. 187-224.

HANSEN, George P. "Max Weber, charisma, and the disenchantment of the world. In: HANSEN, George P. The trickster and the paranormal. Philadelphia: Xlibris, 2001.

LANGA, Patrício. O homem na sociedade ou a sociedade no homem: Ensaio para uma análise sociológica do carisma de Samora Machel. (no prelo)

LINDHOLM, Charles. Carisma: êxtase e perda de identidade na veneração ao líder. Rio de Janeiro: Jorge Zahar, 1993.

MANGHEZI, Alpheus. "Samora Machel: homem do povo". In: SOPA, António (Coord.). Samora, homem do povo. Maputo: Manguezo Editores, 2001.

MAÚNGUE, Hélio et al. Samora na Ilha de Inhaca (1955-1959). Maputo: Imprensa Universitária, 2012.

MAURICIO JUNIOR, Cleonardo. "Revisando o conceito de carisma: lideres pentecostais, entre o virtuosismo e o capital religioso, da dominação à performance". Revista Todavia. Pernambuco, jul., 2011, v. 2, n. 2, p. 42-55. 


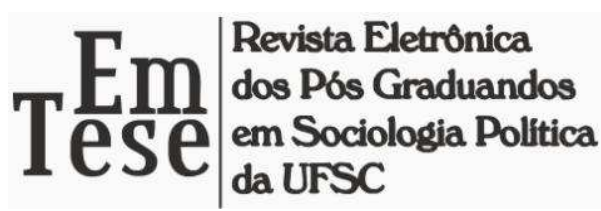

NGOENHA, Severino. Machel ícone da $1^{a}$ república? Maputo: Ndjira, 2009.

SAMORA prosseguiria hoje o seu sonho, talvez com algumas correcções. A Verdade. Maputo, 06 fev. 2012, (Tema de fundo). Disponível em: $<$ http://www.verdade.co.mz/destaques/democracia/24775>.

SILVA, Janine Targino da. A liderança carismática exercida pelas novas líderes pentecostais. Intratextos. Rio de Janeiro, 2010, Número especial, n. 1, p. 151-168.

SCAFF, Lawrence A. Remnants of Romanticism: Max Weber in Oklahoma and Indian Territory. Journal of Classical Sociology. London, 2005, v. 5, n. 1, p. 53-72.

SEGRE, Sandro. A weberian theory of time. Time \& Society. London, 2000, v. 9, n. 2/3, p. $147-170$.

SELL, Carlos Eduardo. A liderança carismática: sobre o caráter político do populismo. (no prelo)

Democracia com liderança: Max Weber e o conceito de democracia plebiscitária. Revista Brasileira de Ciência Política. Brasília, jan.-jul., 2011, n. 5, p. 139-166.

SERRA, C. Combates pela Mentalidade Sociológica. Maputo: Livraria Universitária, 2003.

SOPA, António (Coord.). Samora, homem do povo. Maputo: Maguezo Editores, 2001.

TEMBE, Duarte. Samora: o destino da memória. Maputo: Ndjira, 2000.

WEBER, Max. Ensaios de Sociologia. 4ª ed. Rio de Janeiro: Guanabara, 1982.

. Economia e sociedade: fundamentos de sociologia compreensiva. $3^{\mathrm{a}}$ ed.

Brasília: Unb, vol. 1, 1994.

2001.

- Metodologia das ciências sociais. $4^{\mathrm{a}}$ ed. São Paulo: Editora Cortez, 


\title{
Teme
}

\section{RESUMO}

O presente artigo é uma análise sobre os usos e apropriações feitas da personalidade e qualidades carismáticas de Samora Machel. Pretendemos demonstrar que depois de morto o seu carisma prevalece e perdura no cotidiano, bem como que a relação emocional entre o líder e o povo continua. Apontamos que, nos dias atuais políticos, artistas, bem como cidadãos em geral fazem uso e apropriam-se, de modo racional e calculista, do carisma samoriano para obter benesses. Apontamos também que ainda hoje é Samora que as pessoas apelam e chamam para a resolução da grande maioria dos problemas da sociedade moçambicana. Assim, desencadeia-se um uso e apropriação político, socioeconômico e sociocultural do carisma samoriano. Tal uso e apropriação tornam o carisma um fenômeno objetivado e rotinizado.

PALAVRAS-CHAVE: Samora Machel. Samorismo. Carisma. Apropriação. Moçambique.

\begin{abstract}
This article is the analyses of the uses and appropriations of charismatic personality and qualities of Samora Machel. We intend to demonstrate that after his death his charisma prevails and endures in citizen's daily life, and emotional relationship between the leader and the people continues. We stress out that among the present day politicians, artists, and citizens use and appropriate of the Samora's charisma by rational and calculating manners aim to obtain benefit. We also emphatise that until today people invoke Samora to solve many problems of Mozambican society. Thus, a political, socioeconomic and sociocultural use and appropriation of samorian charisma becomes relieyed. Such use and appropriation make the charisma an objectified and routinized phenomenon.
\end{abstract}

KEYWORDS: Samora Machel. Samorism. Charisma. Appropriation. Mozambique.

Recebido em: 14 de março de 2014

Aceito para publicação em: 08 de junho de 2014 